\title{
Cardiac implantable electronic devices in end-stage renal disease patients: preservation of central venous circulation
}

\author{
Gustavo Lopera • Gerald A. Beathard • Jose Exaire • \\ Roger Carrillo
}

Received: 4 March 2011 / Accepted: 20 November 2011 / Published online: 9 February 2012

(C) Springer Science+Business Media, LLC 2012

Cardiovascular disease is the leading cause of death in patients with end-stage renal disease (ESRD). In the United States Renal Data System database, $25-29.7 \%$ of cardiac deaths are attributable to arrhythmic mechanisms [1, 2]. Ventricular fibrillation (VF) and hemodynamically unstable ventricular tachycardia (VT) likely remain the most common initiating and potentially reversible mechanisms of outof-hospital sudden cardiac death (SCD). Defibrillation is the only predictably effective therapy for reverting VF and pulseless VT to an effective rhythm for restoration of blood flow [3]. The expanding indications of implantable cardioverter-defibrillator (ICD) therapy for primary and secondary prevention of SCD have significantly increased the

\footnotetext{
G. Lopera $\cdot$ R. Carrillo

Division of Cardiology, University of Miami,

Miller School of Medicine,

Miami, FL, USA

G. A. Beathard

University of Texas Medical Branch Galveston,

Galveston, TX, USA

J. Exaire

University of Oklahoma Health Sciences Center,

Oklahoma City, OK, USA

G. Lopera $\cdot$ G. A. Beathard · J. Exaire $\cdot$ R. Carrillo

Division of Cardiothoracic Surgery, University of Miami,

Miller School of Medicine,

Miami, FL, USA

G. Lopera $(\bowtie)$

Miami Veterans Affairs Health Care System,

University of Miami Miller School of Medicine,

1201 N.W. 16th Street,

Miami, FL 33125, USA

e-mail: GLopera@med.miami.edu
}

patient population with cardiac implantable electronic devices (CIEDs) [4].

A meta-analysis of secondary prevention trials showed a $28 \%$ relative risk reduction (RRR) in all-cause mortality ( $p=$ $0.0006)$ with ICD therapy that was due almost entirely to a $50 \%$ RRR in arrhythmic death $(p<0.0001)$; similarly, primary prevention trials showed a $28 \%$ reduction in the risk of death in the ICD-treated patients as compared with the conventionally treated patients and an overall absolute 2year mortality reduction of 3\% [3]. Despite the high incidence of SCD among patients with ESRD and the proven survival benefits of ICD therapy, the benefit of ICD therapy in this patient population has been questioned. This is probably due to the fact that all major ICD trials excluded patients with advanced renal dysfunction and transvenous ICD therapy is associated with higher complications rates in this patient group; especially, on hemodialysis (HD) patients. Our current knowledge regarding the efficacy of ICD therapy in this population relies on observational data and secondary post hoc analyses of major ICD trials [5-11].

Initially, ICDs were implanted via thoracotomy, which was associated with mortality rates of $3 \%$ to $5.4 \%$. The development of transvenous ICD systems in the early 1990 s was associated with an operative mortality of $<1 \%$, lower costs, and shorter hospital stays [12-14]. For these reasons, the transvenous route has become the most frequently used method for implantation of CIEDs. However, the use of the transvenous CIEDs can be associated with significant complications in chronic HD patients including central venous stenosis, tricuspid regurgitation (TR), and device infection [15-31].

Varies degrees of central venous stenosis have been reported in $23 \%$ to $67 \%$ patients with transvenous CIEDs [15-17]. This complication is asymptomatic in most patients. However, the situation is different in patients on 
HD. This population is particularly prone to develop edema of the face, neck, breast, shoulder, and the arm as a consequence of central venous stenosis [18, 19]. Central venous stenosis can also lead to loss of the patient's dialysis access. It is not unusual to encounter patients whose central venous occlusion prevents all upper extremity dialysis access. The presence of significant TR and development of infection of CIEDs in a dialysis patient are also important considerations.

The incidence of CIED-induced TR is largely unknown since the prevalence of TR in "normal" echocardiographic studies ranges from $0 \%$ to $53 \%$ and TR is usually well tolerated in the absence of pulmonary hypertension. Isolated case reports describe severe TR following CIED implantations. Severe TR might be poorly tolerated on HD patients, which are already on cardiac output state due the presence of an arteriovenous fistula. Thus, the development of severe TR can lead to development of right-sided heart failure, which could further complicate their management [20-22].

Reported device infection rates vary widely, from $0.1 \%$ to $19.9 \%$ [23]. However, patients with moderate to severe renal disease exhibit higher device infection rates as compared to the general population [24-26]. Cardiac device infection can be a potentially life-threatening if untreated and can also lead to endocarditis [27, 28]. Device infection usually requires device removal and lead extraction [29].

Infection is the second leading cause of death in endstage renal disease patients [1]. The annual mortality secondary to sepsis is approximately 100 - to 300 -fold higher in dialysis patients compared to the general population [30]. Repeated cannulation of arteriovenous fistulas and the use of tunneled catheters for HD are potential sources for bacteremia in this population. The intravascular location of the CIEDs makes the leads vulnerable to bacterial seeding during HD [31]. In recent years, we have also observed an evolution of implantation techniques of epicardial and subcutaneous CIEDs, making it accessible to patients in whom the traditional transvenous implantation could be associated with high complication rates [32-36].

Among patients treated by HD who also require CIEDs for treatment, the use of an epicardial or subcutaneous approach could decrease the risk of device infection, TR, and central venous stenosis. Therefore, epicardial or subcutaneous CIEDs should be considered in these patients. Recently published preliminary information lends validity to the epicardial approach in HD patients. In this study, the development of CIED infection and central stenosis were markedly reduced after the endocardial devices were removed and replaced with epicardial CIEDs [31]. Bardy et al. reported recently that subcutaneous ICD consistently detected and converted spontaneous and induced VF [36].
In consideration of these facts, the following recommendations are suggested:

1- Epicardial or subcutaneous CIEDs could be offered as treatment alternative to transvenous CIEDs in ESRD patients who meet criteria for CIEDs and are receiving therapy with an arteriovenous fistula or tunneled dialysis catheter. Detail explanation of the indications, risks, and benefits of each therapeutic approach should be shared with patients, if this approach is selected.

2- HD patients with an existing transvenous CIEDs who require laser lead removal for development of device infection or central venous stenosis should be considered for epicardial or subcutaneous CIEDs if device reimplantation is required.

It is important to emphasize that these recommendations represent our personal opinion based on our experience treating patients on HD with CIEDs. Prospective clinical trials are needed to further improve our understanding and establish the best clinical practice in patients with ESRD who also require CEIDs.

\section{References}

1. US Renal Data System: USRDS 2006 Annual Data Report. Bethesda,MD: National Institutes of Health, National Institute of Diabetes and Digestive and Kidney Diseases, 2006.

2. Herzog, C. A., Mangrum, J. M., \& Passman, R. (2008). Sudden cardiac death and dialysis patients. Seminars in Dialysis, 21(4), 300-307.

3. Lopera, G., \& Myerburg, R. (2010). Indications for implantable cardioverter-defibrillators. In G. Yan \& P. Kowey (Eds.), Management of cardiac arrhythmias (pp. 283-304). Chapter 13.

4. ACC/AHA/HRS. (2008). Guidelines for device-based therapy of cardiac rhythm abnormalities: a report of the American College of Cardiology/American Heart Association Task Force on Practice Guidelines (writing committee to revise the ACC/AHA/NASPE 2002 Guideline Update for Implantation of Cardiac Pacemakers and Antiarrhythmia Devices) developed in collaboration with the American Association for Thoracic Surgery and Society of Thoracic Surgeons. Journal of the American College of Cardiology, $51, \mathrm{e} 1-\mathrm{e} 62$.

5. Korantzopoulos, P., Liu, T., Li, L., Goudevenos, J. A., \& Li, G. (2009). Implantable cardioverter defibrillator therapy in chronic kidney disease: a meta-analysis. Europace, 11, 1469-1475.

6. Cuculich, P. S., Sánchez, J. M., Kerzner, R., Greenberg, S. L., Sengupta, J., Chen, J., Faddis, M. N., Gleva, M. J., Smith, T. W., \& Lindsay, B. D. (2007). Poor prognosis for patients with chronic kidney disease despite ICD therapy for the primary prevention of sudden death. Pacing and Clinical Electrophysiology, 30, 207213.

7. Amin, M. S., Fox, A. D., Kalahasty, G., Shepard, R. K., Wood, M. A., \& Ellenbogen, K. A. (2008). Benefit of primary prevention implantable cardioverter-defibrillators in the setting of chronic kidney disease: a decision model analysis. Journal of Cardiovascular Electrophysiology, 19, 1275-1280. 
8. Robin, J., Weinberg, K., Tiongson, J., Carnethon, M., Reddy, M., Ciaccio, C., Quadrini, M., Hsu, J., Fan, J., Choi, P., Kadish, A., Goldberger, J., \& Passman, R. (2006). Renal dialysis as a risk factor for appropriate therapies and mortality in implantable cardioverter-defibrillator recipients. Heart Rhythm, 3(10), 11961201. Epub 2006 Jul 8.

9. Goldenberg, I., \& Moss, A. J. (2008). Implantable cardioverter defibrillator efficacy and chronic kidney disease: competing risks of arrhythmic and nonarrhythmic mortality. Journal of Cardiovascular Electrophysiology, 19(12), 1281-1283.

10. Turakhia, M. P., Varosy, P. D., Lee, K., Tseng, Z. H., Lee, R., Badhwar, N., Scheinman, M., Lee, B. K., \& Olgin, J. E. (2007). Impact of renal function on survival in patients with implantable cardioverter-defibrillators. Pacing and Clinical Electrophysiology, 30(3), 377-384.

11. Hiremath, S., Punnam, S. R., Brar, S. S., Goyal, S. K., Gardiner, J. C., Shah, A. J., \& Thakur, R. K. (2010). Implantable defibrillators improve survival in end-stage renal disease: results from a multi-center registry. American Journal of Nephrology, 32(4), 305-310.

12. Manolis, A. S. (1994). Transvenous endocardial cardioverter defibrillator systems. Is the future here? Archives of Internal Medicine, 154(6), 617-622.

13. Zipes, D. P., \& Roberts, D. (1995). Results of the international study of the implantable pacemaker cardioverter-defibrillator. A comparison of epicardial and endocardial lead systems. The Pacemaker-Cardioverter-Defibrillator Investigators. Circulation, 92(1), 59-65.

14. Saksena, S. (1993). Defibrillation thresholds and perioperative mortality associated with endocardial and epicardial defibrillation lead systems. The PCD investigators and participating institutions. Pacing and Clinical Electrophysiology, 16(1 Pt 2), 202-207.

15. van Rooden, C. J., Molhoek, S. G., Rosendaal, F. R., Schalij, M. J., Meinders, A. E., \& Huisman, M. V. (2004). Incidence and risk factors of early venous thrombosis associated with permanent pacemaker leads. Journal of Cardiovascular Electrophysiology, 15(11), 1258-1262.

16. Lickfett, L., Bitzen, A., Arepally, A., Nasir, K., Wolpert, C., Jeong, K. M., Krause, U., Schimpf, R., Lewalter, T., Calkins, H., Jung, W., \& Lüderitz, B. (2004). Incidence of venous obstruction following insertion of an implantable cardioverter defibrillator. A study of systematic contrast venography on patients presenting for their first elective ICD generator replacement. Europace, 6(1), 25-31.

17. Haghjoo, M., Nikoo, M. H., Fazelifar, A. F., Alizadeh, A., Emkanjoo, Z., \& Sadr-Ameli, M. A. (2007). Predictors of venous obstruction following pacemaker or implantable cardioverter-defibrillator implantation: a contrast venographic study on 100 patients admitted for generator change, lead revision, or device upgrade. Europace, 9 (5), 328-332. Epub 2007 Mar 16.

18. Teruya, T. H., Abou-Zamzam, A. M., Jr., Limm, W., Wong, L., \& Wong, L. (2003). Symptomatic subclavian vein stenosis and occlusion in hemodialysis patients with transvenous pacemakers. Annals of Vascular Surgery, 17(5), 526-529.

19. Korzets, A., Chagnac, A., Ori, Y., Katz, M., \& Zevin, D. (1991). Subclavian vein stenosis, permanent cardiac pacemakers and the haemodialysed patient. Nephron, 58(1), 103-105.

20. Lin, G., Nishimura, R. A., Connolly, H. M., Dearani, J. A., Sundt, T. M., 3rd, \& Hayes, D. L. (2005). Severe symptomatic tricuspid valve regurgitation due to permanent pacemaker or implantable cardioverter-defibrillator leads. Journal of the American College of Cardiology, 45(10), 1672-1675.

21. Iskandar, S. B., Ann Jackson, S., Fahrig, S., Mechleb, B. K., \& Garcia, I. D. (2006). Tricuspid valve malfunction and ventricular pacemaker lead: case report and review of the literature. Echocardiography, 23(8), 692-697.
22. Paniagua, D., Aldrich, H. R., Lieberman, E. H., Lamas, G. A., \& Agatston, A. S. (1998). Increased prevalence of significant tricuspid regurgitation in patients with transvenous pacemakers leads. The American Journal of Cardiology, 82(9), 1130-1132.

23. Baddour, L. M., Epstein, A. E., Erickson, C. C., Knight, B. P., Levison, M. E., Lockhart, P. B., Masoudi, F. A., Okum, E. J., Wilson, W. R., Beerman, L. B., Bolger, A. F., Estes, N. A., 3rd, Gewitz, M., Newburger, J. W., Schron, E. B., \& Taubert, K. A. (2010). Update on cardiovascular implantable electronic device infections and their management: a scientific statement from the American Heart Association. American Heart Association Rheumatic Fever, Endocarditis, and Kawasaki Disease Committee; Council on Cardiovascular Disease in Young; Council on Cardiovascular Surgery and Anesthesia; Council on Cardiovascular Nursing; Council on Clinical Cardiology; Interdisciplinary Council on Quality of Care; American Heart Association. Circulation, 121(3), 458-477.

24. Bloom, H., Heeke, B., Leon, A., Mera, F., Delurgio, D., Beshai, J., \& Langberg, J. (2006). Renal insufficiency and the risk of infection from pacemaker or defibrillator surgery. Pacing and Clinical Electrophysiology, 29(2), 142-145.

25. Baman, T. S., Gupta, S. K., Valle, J. A., \& Yamada, E. (2009). Risk factors for mortality in patients with cardiac device-related infection. Circulation. Arrhythmia and Electrophysiology, 2(2), 129134.

26. Lekkerkerker, J. C., van Nieuwkoop, C., Trines, S. A., van der Bom, J. G., Bernards, A., van de Velde, E. T., Bootsma, M., Zeppenfeld, K., Jukema, J. W., Borleffs, J. W., Schalij, M. J., \& van Erven, L. (2009). Risk factors and time delay associated with cardiac device infections: Leiden device registry. Heart, 95(9), 715-720. Epub 2008 Nov 26.

27. Uslan, D. Z. (2008). Infections of electrophysiologic cardiac devices. Expert Review of Medical Devices, 5(2), 183-195. Review.

28. Greenspon, A. J., Rhim, E. S., Mark, G., Desimone, J., \& Ho, R. T. (2008). Lead-associated endocarditis: the important role of methicillin-resistant Staphylococcus aureus. Pacing and Clinical Electrophysiology, 31(5), 548-553.

29. Wilkoff, B. L., Love, C. J., Byrd, C. L., Bongiorni, M. G., Carrillo, R. G., Crossley, G. H., 3rd, Epstein, L. M., Friedman, R. A., Kennergren, C. E., Mitkowski, P., Schaerf, R. H., Wazni, O. M., \& Heart Rhythm Society; American Heart Association. (2009). Transvenous lead extraction: Heart Rhythm Society expert consensus on facilities, training, indications, and patient management: this document was endorsed by the American Heart Association (AHA). Heart Rhythm, 6(7), 1085-1104.

30. Sarnak, M. J., \& Jaber, B. L. (2000). Mortality caused by sepsis in patients with end-stage renal disease compared with the general population. Kidney International, 58(4), 1758-1764.

31. Asif, A., Carrillo, R., Garisto, J.D., Lopera, G., Ladino, M., Barakat, U., Eid, N., Salman, L. (2010). Epicardial Cardiac rhythm devices for dialysis patients: minimizing the risk of infection and preserving central veins. Seminars in Dialysis.

32. Gabor, S., Prenner, G., Wasler, A., Schweiger, M., Tscheliessnigg, K. H., \& Smolle-Jüttner, F. M. (2005). A simplified technique for implantation of left ventricular epicardial leads for biventricular re-synchronization using video-assisted thoracoscopy (VATS). European Journal of Cardio-Thoracic Surgery, 28(6), 797-800

33. Cannon, B. C., Friedman, R. A., Fenrich, A. L., Fraser, C. D., McKenzie, E. D., \& Kertesz, N. J. (2006). Innovative techniques for placement of implantable cardioverter-defibrillator leads in patients with limited venous access to the heart. Pacing and Clinical Electrophysiology, 29(2), 181-187.

34. Bhakta, M., Obioha, C. C., Sorajja, D., Srivathsan, K., Arabia, F. A., Devaleria, P. A., Jaroszewski, D. E., Scott, L. R., \& Altemose, 
G. T. (2010). Nontraditional implantable cardioverter defibrillator placement in adult patients with limited venous access: a case series. Pacing and Clinical Electrophysiology, 33(2), 217225.

35. Molina, J. E., \& Benditt, D. G. (2004). An epicardial subxiphoid implantable defibrillator lead: superior effectiveness after failure of standard implants. Pacing and Clinical Electrophysiology, 27(11), $1500-1506$.
36. Bardy, G. H., Smith, W. M., Hood, M. A., Crozier, I. G., Melton, I. C., Jordaens, L., Theuns, D., Park, R. E., Wright, D. J., Connelly, D. T., Fynn, S. P., Murgatroyd, F. D., Sperzel, J., Neuzner, J., Spitzer, S. G., Ardashev, A. V., Oduro, A., Boersma, L., Maass, A. H., Van Gelder, I. C., Wilde, A. A., van Dessel, P. F., Knops, R. E., Barr, C. S., Lupo, P., Cappato, R., \& Grace, A. A. (2010). An entirely subcutaneous implantable cardioverter-defibrillator. The New England Journal of Medicine, 363(1), 36-44. 